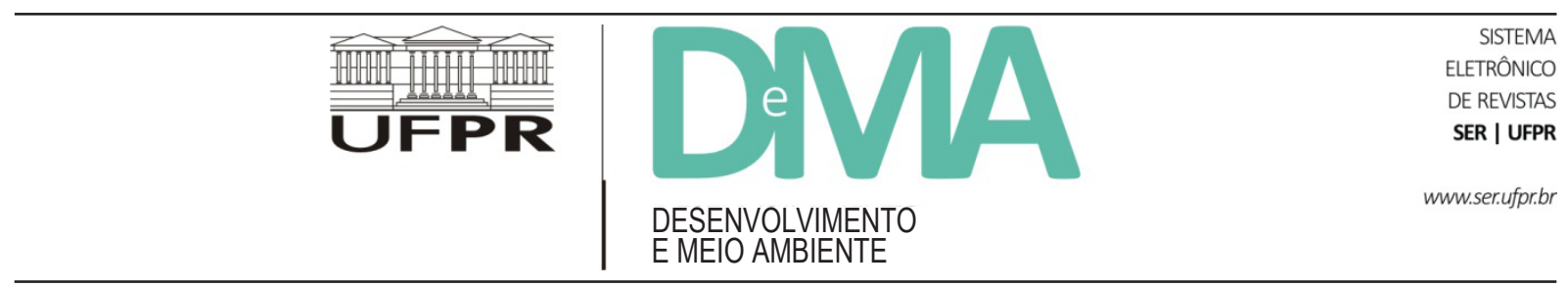

\title{
Pluriatividade e sustentabilidade em comunidades rurais do semiárido nordestino
}

\section{Pluriactivity and Sustainability in Rural Communities of Semiarid Northeast}

\author{
Valcilene Rodrigues da SILVA ${ }^{1 *}$, Marlene Maria da SILVA ${ }^{1}$, Mônica Cox de Britto PEREIRA ${ }^{1}$ \\ ${ }^{1}$ Programa de Pós-graduação em Desenvolvimento e Meio Ambiente (PRODEMA), Universidade Federal de Pernambuco (UFPE), Recife, \\ PE, Brasil. \\ *E-mail de contato: valcilener@gmail.com
}

Artigo recebido em 25 de março de 2015, versão final aceita em 9 de novembro de 2015.

RESUMO: O ambiente rural e a agricultura brasileira vêm apresentando um processo intenso de transformações nas últimas décadas. Tais transformações têm gerado muitos debates nos meios político, econômico e acadêmico, dentre os quais está a noção de pluriatividade, um termo recente que designa o agricultor familiar que, residindo no meio rural, combina atividades agrícolas com atividades não agrícolas, como forma de complementar a renda familiar. A pesquisa buscou analisar como a pluriatividade se apresenta em comunidades rurais do semiárido nordestino e como essa prática interfere na sustentabilidade social, econômica e ecológica das comunidades estudadas. Para alcançar este objetivo, utilizou-se o método dialético como método científico e, como procedimentos metodológicos, entrevistas semiestruturadas com representantes de órgãos públicos locais e com as famílias pluriativas das comunidades. Dentro do cenário de semiárido nordestino, a referência empírica do estudo foram três comunidades rurais do município de Brejinho/PE: Sítio Caldeirão, Sítio Lagoa dos Campos e Vila de Fátima. A análise dos resultados indica que a pluriatividade tem um papel fundamental na sustentabilidade social, econômica e ambiental das comunidades pesquisadas. No entanto, não pode ser considerada como a solução para os problemas rurais, visto que muitas famílias do semiárido ainda têm sua reprodução social e econômica ameaçada e solos em processo de degradação. Logo, muitos desafios ainda precisam ser vencidos para se ter um semiárido sustentável.

Palavras-chave: pluriatividade; agricultura familiar; sustentabilidade; semiárido.

ABSTRACT: The rural environment and Brazilian agriculture have been showing an intense process of transformations in recent decades. These changes have generated many debates in political, economic and academic circles, among which there is the notion of pluriactivity, a recent term for the family farmer that, residing in rural areas, combines agricultural activities with non-agricultural activities as a way to supplement the family income. The research sought to analyze how the pluriactivity is presented in rural communities of semiarid northeast and how this practice interferes in the social, economic and ecological sustainability of the communities 
studied. To achieve this goal, the dialectical method was used as the scientific method, and semi-structured interviews with representatives of local government agencies and the pluriactive families of the communities were used as methodological procedures. Inside the semiarid northeastern scenario, the empirical references of the study were three rural communities in the municipality of Brejinho/PE: Sítio Caldeirão, Sítio Lagoa dos Campos and Vila de Fátima. The analysis of the results indicates that the pluriactivity has a key role in social, economic and environmental sustainability of the communities surveyed. However, it cannot be considered as the solution to rural problems, as many families in the semiarid region still have their social and economic reproduction threatened, and soils in the process of degradation. Thus, many challenges remain to be overcome to achieve a sustainable semiarid region.

Keywords: pluriactivity; family farming; sustainability; semiarid region.

\section{Introdução}

O ambiente rural e a agricultura brasileira vêm apresentando um processo intenso de transformação nas últimas décadas. Dentre essas transformações se destacam a migração da população rural para áreas urbanas, alterações produtivas da agricultura e, consequentemente, mudanças nas relações dos agricultores com os meios rural e urbano, principalmente no que diz respeito às atividades praticadas e à renda. Tais mudanças têm gerado muitos debates nos meios político, econômico e acadêmico, dentre os quais sobressai o debate em torno da noção de pluriatividade, termo recente que designa o agricultor familiar que, residindo no meio rural, combina atividades agrícolas com atividades não agrícolas como forma de complementar a renda familiar e se reproduzir socialmente (Schneider, 2009a; 2009b).

Apesar de ser bastante discutida na região Sul do Brasil desde os anos 1990, no Nordeste ainda existem lacunas no estudo da temática da pluriatividade. $\mathrm{Na}$ tentativa de suprir uma dessas lacunas, o presente artigo, que é fruto de uma dissertação de mestrado, teve por objetivo analisar como a pluriatividade se apresenta e como essa prática interfere na sustentabilidade social, econômica e ecológica de comunidades rurais do semiárido nordestino.

Dentro do cenário semiárido, a referência empírica do estudo foram três comunidades rurais do Município de Brejinho/ $\mathrm{PE}^{1}$ : Sítio Caldeirão, Sítio Lagoa dos
Campos e Vila de Fátima (Figura 1). A escolha dessas áreas foi motivada pelo fato de Brejinho/PE ser um dos seis municípios integrantes do projeto guarda-chuva do Programa de Pós-Graduação em Desenvolvimento e Meio Ambiente (PRODEMA) da Universidade Federal de Pernambuco (UFPE) e por ser a autora natural do município, tendo nascido e crescido no Sítio Caldeirão.

Considerando que as coisas não acontecem de forma isolada e independente e que, por isso, os fenômenos só podem ser compreendidos dentro de seu contexto histórico e social, vistos a partir de sua totalidade e de modo sistêmico, adotou-se o método dialético na abordagem da pluriatividade. Para Sposito (2004), o método dialético busca entender a realidade a partir das contradições, oposições e conflitos estabelecidos. A pluriatividade na agricultura familiar tem tudo a ver com esse processo totalizante, onde existem interdependência e ação recíproca, devendo, portanto, ser explicada considerando-se os fenômenos que estão a sua volta.

Quanto aos procedimentos metodológicos, a pesquisa abrange três etapas: na primeira, foram realizadas duas visitas nas comunidades, em julho e setembro de 2013, para realizar a pesquisa exploratória e a caracterização da área de estudo. A segunda etapa aconteceu em março de 2014, com a realização de entrevistas semiestruturadas com representantes do poder público local. $\mathrm{Na}$ terceira etapa, em agosto de 2014, foram realizadas trinta (30) entrevistas semiestruturadas com famílias das três comunidades estudadas. Os critérios de seleção

\footnotetext{
Embora para o IBGE as localidades Sítio Caldeirão e Sítio Lagoa dos Campos figurem em Setor Censitário do Município de São José do Egito/PE, tanto as citadas comunidades como a administração municipal consideram-nas integrantes do Município de Brejinho, problema esse que os dois municípios estão procurando solucionar junto aos órgãos competentes.
} 


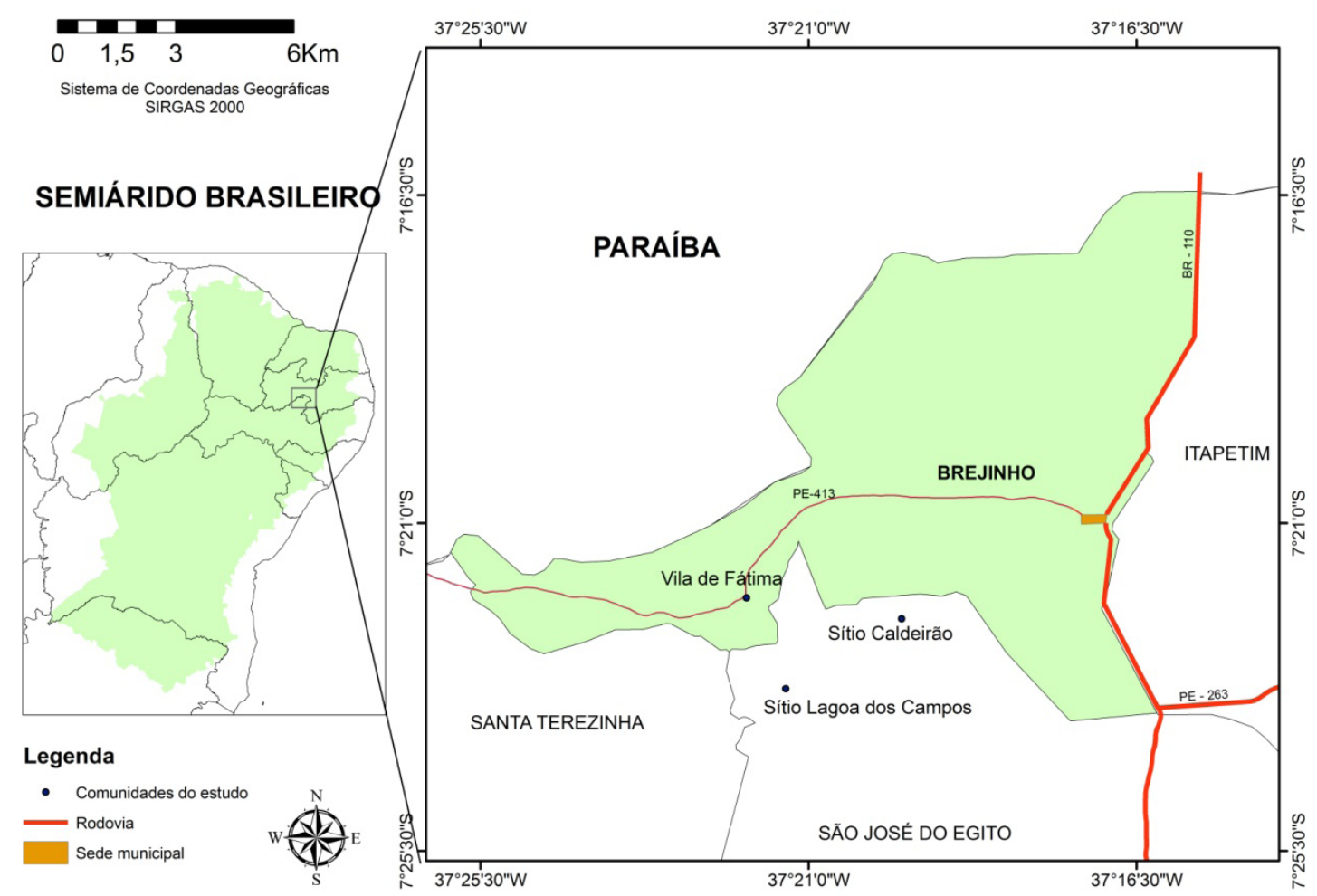

FIGURA 1 - Localização Geográfica das Comunidades do Estudo.

FONTE: IBGE, arquivo shape, 2000. Elaboração: Valcilene Rodrigues, 2015.

dos entrevistados foram: famílias que exercessem a combinação de atividades agrícolas e não agrícolas, que residissem no meio rural e tivessem propriedade ou posse da terra.

$\mathrm{Na}$ análise e tratamento dos dados, a sustentabilidade foi vista a partir de três dimensões e para cada dimensão foram selecionados alguns indicadores: a) dimensão ecológica - diversidade de culturas; tipo de adubação praticada; defensivo agrícola utilizado; tamanho da terra; disponibilidade de água e desmatamento; b) dimensão social - características da moradia; disponibilidade de meios de transporte; acesso a meios de comunicação; educação; segurança; e segurança alimentar; c) dimensão econômica - ocupação da força de trabalho; e renda. Tais indicadores foram adaptados para o contexto do semiárido e analisados, sobretudo, de forma qualitativa, tomando-se como base a pesquisa de campo.
Como técnica de análise foi adotada a análise de conteúdo (Bardin, 2009), onde os dados foram sistematizados, tabulados e representados em gráficos para fundamentar as análises realizadas com vistas a evidenciarem as relações existentes entre a pluriatividade e a sustentabilidade da realidade em estudo.

\section{Perspectivas históricas e conceituais da pluriatividade}

No Brasil, a pluriatividade só vem ganhar espaço na agenda dos pesquisadores a partir de 1990, especialmente na região Sul do país. No entanto, o termo resulta do amadurecimento teórico de outras terminologias, como Multiple job holding, farming diversification e part time farming, já utilizadas, desde a década de 1970, 
por autores que estudavam a presença de atividades não agrícolas no meio rural europeu. De acordo com Maria José Carneiro (1998, p. 157), a pluriatividade é "uma criação recente do vocabulário técnico da qual o campo acadêmico se apropriou" e a amplitude do fenômeno sugere questões importantes sobre as condições de reprodução da agricultura familiar. Nesse sentido, o debate acadêmico apresenta duas direções: para alguns estudiosos, o agricultor familiar sempre recorreu a formas complementares de renda, sendo a pluriatividade, na verdade, uma relação social antiga. Isso gera questionamento quanto à pertinência ou não do termo pluriatividade para identificar o conjunto de práticas diversificadas que caracterizam muito mais um estilo de vida e mecanismos de manutenção das famílias do que uma nova forma de exploração. Para outros, a pluriatividade é recriada para afrontar as crises geradas pela modernização da agricultura, apontando para novas categorias sociais no campo, sendo, portanto, um fenômeno recente e transitório.

A concepção de Carneiro (1998) é que a pluriatividade é tanto um fenômeno antigo como recente. A combinação da agricultura com atividades como o artesanato e trabalhos efetuados para terceiros sempre esteve presente na sociedade rural. Logo, desse ponto de vista, a pluriatividade pode ser considerada um fenômeno antigo que, até então, não foi considerado um campo de estudo porque tais atividades confundiam-se com as numerosas práticas do mundo rural. Por outro lado, é um fenômeno recente quando analisadas as características específicas decorrentes dos contextos econômico e social atuais (modernização tecnológica, queda das rendas agrícolas, dinâmica do mercado de trabalho).

Tendo em conta o contexto da realidade semiárida, onde a agricultura familiar sempre esteve associada a diversas formas de complementação de renda, como costura, pesca, caça, artesanato e prestação de serviços a terceiros, e considerando as transformações desse espaço, nas últimas décadas, com o processo de modernização agrícola (envolvendo implantação de áreas irrigadas, mudanças na base agropecuária e o processo de urbanização crescente), concorda-se, neste caso, com a concepção de Carneiro (1998), segundo a qual a pluriatividade pode ser um fenômeno tanto antigo quanto recente. Isto com a ressalva de Schneider (2009a), de que a pluriatividade não é um fenômeno transitório e nem representa um processo com tendência à generalização das atividades não agrícolas para todas as áreas rurais.

Para Schneider (2009a), a pluriatividade é um fenômeno heterogêneo e diversificado que está ligado, de um lado, às estratégias sociais e produtivas adotadas pela família e por seus membros e, de outro, depende das características do contexto em que estiver inserido. Ainda de acordo com o autor, a pluriatividade se caracteriza pela combinação de múltiplas inserções ocupacionais das pessoas que pertencem a uma mesma família, sendo uma delas a agricultura.

Schneider (2009a) mostra ainda que a interação entre as atividades agrícolas e não agrícolas tende a ser mais intensa quanto mais complexas e diversificadas forem as relações entre os agricultores e o ambiente socioeconômico no qual estão situadas. Enfatiza que a integração ao mercado pelos membros das famílias passa a acontecer, também, pela via do mercado de trabalho e não mais apenas por seus produtos, ou seja, a venda da força de trabalho passa a ser mercadoria de troca dos agricultores com o mercado. Sacco dos Anjos (2003) contribui ao lembrar que essas atividades podem ser desenvolvidas tanto dentro como fora do estabelecimento rural, por meio da venda da força de trabalho familiar, da prestação de serviços para outros agricultores ou iniciativas centradas no próprio estabelecimento, de modo que ocorra o aproveitamento de todas as potencialidades existentes na propriedade ou seu entorno.

Carneiro (1998) afirma que a pluriatividade não pode ser explicada levando em consideração apenas a sua dimensão econômica, mas, também, devem ser levados em conta alguns fatores, como localização em relação aos centros urbanos-industriais, características geográficas e a ação do Estado através de políticas para o desenvolvimento rural, que se articulam com as diferenças culturais para formar a produção agrícola. No caso do semiárido, acrescentam-se, ainda, os fatores climáticos como essenciais para analisar o contexto da pluriatividade, uma vez que as atividades agrícolas nas unidades familiares, geralmente, não dispõem de irrigação, sendo, por isso, totalmente dependentes dos fatores climáticos. A existência de estiagens, por exemplo, causa prejuízo na produção agrícola, o que pode impulsionar a família a recorrer a atividades não agrícolas no período. 
Assim, pode-se dizer que a noção de pluriatividade não designa um fenômeno específico, visto que existem inúmeras possibilidades de se praticar a atividade não agrícola no interior da unidade familiar agrícola (Carneiro, 1998) e, também, inúmeras formas de analisar esse processo. Portanto, no presente trabalho, a pluriatividade é considerada como sendo a combinação de atividades agrícolas e não agrícolas, assalariadas ou não, dentro da propriedade ou fora dela, que sejam exercidas por pessoas pertencentes à mesma família e que mantenham residência no estabelecimento rural.

\section{Debate da sustentabilidade para o semiárido}

Os termos desenvolvimento sustentável e sustentabilidade vêm sendo muito discutidos nas últimas décadas. Para Sachs (1989), o desenvolvimento sustentável se baseia numa visão holística da realidade, ou seja, na visão do mundo como um todo integrado e não como um conjunto de partes dissociadas. $\mathrm{O}$ autor aponta como critérios básicos para o desenvolvimento sustentado: o da justiça social, critério ético de solidariedade com as gerações presentes; o da prudência ecológica, critério ético de solidariedade com as futuras gerações; e o de eficiência econômica, que deve ser benéfica para a população consumidora e poupadora dos recursos naturais.

De um ponto de vista mais operacional, Buarque (1995) afirma que o desenvolvimento sustentável é um processo de mudança social e elevação das oportunidades da sociedade. Esse desenvolvimento deve compatibilizar, no tempo e no espaço, o crescimento e a eficiência econômica, a conservação ambiental, a qualidade de vida e a equidade social, partindo de um claro compromisso com o futuro e a solidariedade entre gerações.

Foladori $(2002 ; 2007)$ chama a atenção para três dimensões da sustentabilidade ${ }^{2}$ : a dimensão ecológica, a dimensão econômica e a dimensão social. Para o autor, nessas dimensões estariam incluídas todas as preocupações ambientais, de maneira que as questões ambientais não podem ser reduzidas à poluição e à contaminação, mas devem incluir a pobreza, a desigualdade e outras variáveis sociais.
Sachs (1993) e Foladori (2002) afirmam que a sustentabilidade ecológica compreende o uso dos potenciais inerentes aos variados ecossistemas compatíveis com sua mínima deterioração, dizendo respeito a certo equilíbrio e manutenção de ecossistemas. A sustentabilidade ecológica deve permitir que a natureza encontre novos equilíbrios por meio de processos de utilização que obedeçam a seu ciclo temporal, o que implicaria, também, a preservação das fontes de recursos energéticos e naturais. Como é um mito pensar na natureza sem pessoas (Diegues, 1996), a sustentabilidade ecológica requer ações, metas e estratégias que sejam conjuntas e conscientizem o homem da responsabilidade de conservar esses recursos para as próximas gerações.

A sustentabilidade social é aquela que reduz, substancialmente, as diferenças sociais e considera o desenvolvimento em sua multidimensionalidade, abrangendo todo o espectro de necessidades materiais e não materiais (Sachs, 1993). Isto inclui a necessidade de se removerem todas as fontes de privação de liberdade, como pobreza, tirania, carência de oportunidades econômicas, negligência dos serviços públicos, dentre outras (Sen, 2010).

Para Foladori (2002), a dimensão social da sustentabilidade é a mais polêmica. Durante décadas, pobreza e crescimento populacional foram considerados como causa da insustentabilidade ecológica e não como um problema em si. Para o autor, nem sempre é fácil distinguir as questões sociais das ecológicas. Ele cita como exemplo o processo de erosão do solo, entendido como um problema de insustentabilidade ecológica, mas que, causado pelo cultivo em terras marginais e por comunidades pobres, torna-se, simultaneamente, um problema de insustentabilidade social.

Como a dimensão econômica está associada às outras dimensões, logo, um transtorno econômico traz como consequência um transtorno social que, por sua vez, interrompe a sustentabilidade ecológica (Sachs, 2008). Foladori (2002) argumenta que essa dimensão está associada ao crescimento econômico e à eficiência produtiva, totalmente comandada pelo sistema capitalista. Assim, pela falta de outro sistema para substituir o capitalismo, a visão da economia ecológica sugere

${ }^{2} \mathrm{O}$ autor inclui outras dimensões, como a política e a cultural, na dimensão social. 
medidas mitigadoras, como corrigir os processos produtivos, substituindo os recursos naturais não renováveis por renováveis e reduzir, crescentemente, a poluição, para alcançar um desenvolvimento "mais sustentável".

No caso do semiárido, especialmente na agricultura familiar, observa-se que as condições de reprodução socioeconômica dos agricultores e o tamanho reduzido das propriedades dificultam o uso racional dos recursos naturais. Além disso, o semiárido tem ecossistemas que possuem características ambientais naturais com limites para cultivos agrícolas. Quando esses limites não são respeitados, os impactos negativos irão surgir (Duque, 2004).

A (in)sustentabilidade social, ecológica e econômica no semiárido esteve, por muito tempo, relacionada à problemática da seca. Logo, as alternativas para modificação da realidade regional foram de combate aos efeitos da seca e de aumento da produção/produtividade econômica, sobretudo com base na irrigação. Tal visão reducionista, fundamentada no progresso técnico e no domínio da natureza, começa a mudar quando vários atores sociais percebem o semiárido como um espaço onde é possível construir ou resgatar relações de convivência entre o homem e a natureza (Silva, 2006). Uma visão segundo a qual o homem não é externo à natureza, mas um de seus elementos.

Concordando com Silva (2006), entende-se que o conceito de sustentabilidade para o semiárido deve estar associado ao "paradigma da convivência" - um olhar que reconhece as fragilidades da região, mas quebra a visão de "região problema dominada pela seca". Como afirma Malvezzi (2007), a convivência consiste em compreender como o clima funciona e adequar-se a ele. É preciso interferir no ambiente, mas respeitando as leis do ecossistema.

Assim, qualquer modelo de sustentabilidade para o semiárido, respaldado na lógica da convivência, deve ter como premissas:

a) o compromisso com as necessidades e potencialidades da população local; b) a conservação e o uso sustentável da biodiversidade; c) a recuperação das áreas degradadas; d) a quebra do monopólio da terra e da água; e) a valorização do patrimônio cultural, étnico, material e simbólico do semiárido; e) o reconhecimento da agricul- tura familiar como categoria sociopolítica e estratégica do desenvolvimento e o reconhecimento do meio rural como território de produção e reprodução da vida; f) a valorização das tradições e conhecimentos das comunidades; g) o reconhecimento da diversidade étnica e cultural do semiárido com seu patrimônio, colocando sua população como coautora das políticas e não como sua simples beneficiária (Baptista \& Campos, 2013a, p. 32).

Em face do exposto, nota-se que essa concepção de sustentabilidade tem como protagonista principal a população da região e expressa a possibilidade de resgatar relações de convivência entre as pessoas e a natureza. Nesse sentido, a presente pesquisa avalia como a pluriatividade impacta na sustentabilidade das comunidades estudadas com base na lógica da convivência com o semiárido. Para isso, se faz necessário conhecer as principais características e transformações recentes da região, abordadas a seguir.

\section{Características e transformações recentes da região semiárida}

O semiárido brasileiro apresenta-se como uma realidade dinâmica, complexa e multifacetada. É um verdadeiro mosaico com características peculiares e, por isso, precisa ser compreendido sob múltiplos olhares e dimensões (Malvezzi, 2007). A construção simbólica do termo semiárido é nova e difere de Nordeste, espaço associado à falta de água, morte de animais, crianças desnutridas, fome, êxodo, pessoas incapazes, indústria da seca. Configura uma imagem positiva, associada à ideia de convivência com as características que lhes são peculiares (Barbosa, 2010). O semiárido “[...] não é apenas clima, vegetação, solo, sol, água. É povo, música, festa, arte, religião, política, história. [...] Traz consigo uma identidade cultural para além do clima e do bioma" (Malvezzi, 2007, p. 9).

De acordo com dados do Ministério da Integração Nacional, a região semiárida brasileira abrange, com a nova delimitação, aproximadamente $11 \%$ do território nacional, sendo considerado o semiárido mais povoado e chuvoso do planeta. Engloba oito estados nordestinos: Alagoas, Bahia, Ceará, Paraíba, Pernambuco, Piauí, 
Rio Grande do Norte e Sergipe, e parte de Minas Gerais, no Sudeste, totalizando uma extensão territorial de $980.133,079 \mathrm{~km}^{2}$ (Brasil, 2004). Contava, em 2010, com uma população de 22.598.318 habitantes, dos quais $38,03 \%$ residiam no meio rural (INSA, 2012).

A cobertura vegetal é predominantemente composta pelo bioma Caatinga, único bioma exclusivamente brasileiro, que apresenta enorme variedade de paisagens, riqueza biológica e endemismo (Aziz Ab'Saber, 2003). Com forte insolação, altas temperaturas e elevadas taxas de evapotranspiração, além de baixos e irregulares índices pluviométricos, o semiárido brasileiro é uma região altamente vulnerável à estiagem (Barbosa, 2010). É evidente que as características climáticas influenciam, fortemente, as demais condições naturais da região recursos hídricos, solos, relevo, vegetação e multiplicidade de espécies que compõem sua biodiversidade. No entanto, a estiagem não é o principal problema da região. As características ambientais têm contribuído para fortalecer concepções e posturas de desprezo por esse território, mas, na verdade, as causas e raízes de tais problemas são estruturais e políticas, criadas por grupos com interesses pessoais que, ao longo da história, construíram o paradigma da "indústria da seca" para manter seus privilégios, como a concentração de terra (Baptista \& Campos, 2013b; Conti, 2013). Daí, a lógica veiculada de que é necessário combater a seca ao invés de conviver com a mesma, como ensina o próprio bioma.

$\mathrm{Na}$ lógica de combate à seca, o resultado das políticas governamentais foi simplesmente a retenção da massa populacional na região por meio das frentes de emergência e distribuição de cestas básicas (SUDENE, 1967). Do mesmo modo, as políticas de modernização agrícola não atenderam à categoria agricultores familiares, evidenciando, assim, que a modernização na região foi um processo restrito, mantendo o padrão tradicional dominante, consolidando, ainda mais, a grande propriedade (Araújo, 2000).

Apesar desse histórico, ocorreram, na última década do século XX, mudanças significativas nas formas de intervenção no semiárido para superação das problemáticas socioeconômica e ecológica. Dentre tais mudanças, encontra-se a passagem das políticas de combate à seca e assistencialismo para políticas de convivência com a realidade semiárida. São exemplos de políticas públicas que vêm contribuindo para a convivência com o semiárido: a) o Programa Um Milhão de Cisternas (P1MC), implementado em 2003, que prevê a construção de um milhão de cisternas para consumo humano; b) o Programa Uma Terra e Duas Águas (P1+2), criado em 2007 com o objetivo de implementar outras tecnologias sociais de captação de água de chuva para produção de alimentos e diversos usos; c) o Programa Nacional de Fortalecimento da Agricultura Familiar (PRONAF), que tem evoluído, significativamente, nos últimos anos, passando de um montante de pouco menos de R \$ 3,3 bilhões no período 1999/2000 (Brasil, 2014a) para 24,1 bilhões no Plano Safra 2014/2015 (Brasil, 2014b); d) o Garantia Safra, que é uma ação do PRONAF voltada para agricultores familiares que se encontram em municípios sujeitos a perdas de safra devido à seca ou ao excesso de chuvas; e) o Programa de Aquisição de Alimentos (PAA) e o Programa Nacional de Alimentação Escolar (PNAE), cujo público fornecedor é constituído por agricultores enquadrados no PRONAF; f) o Programa Bolsa Família (PBF), que é um programa de transferência direta de renda que beneficia famílias em situação de pobreza e de extrema pobreza que, embora não seja uma política regional, tem $50 \%$ das famílias beneficiadas no Nordeste (Brasil, 2014c); e g) a chegada da previdência social rural, representando um vigoroso avanço em termos de universalização do sistema previdenciário, redução das desigualdades e erradicação da pobreza absoluta no Brasil (Beltrão et al., 2000).

Vale ressaltar que, apesar dos avanços nas políticas públicas, ainda existem muitos desafios a serem superados no que se refere às políticas capazes de promover o acesso aos meios de produção, como terra em quantidade e qualidade suficientes, tecnologias apropriadas para a região e assistência técnica.

No que diz respeito à dinâmica econômica, nota-se que, assim como as políticas públicas, a economia nordestina vem sofrendo mudanças importantes nas últimas décadas, dentre as quais se destacam a crise do tripé gado/algodão/lavouras alimentares, a mudança do perfil produtivo da agropecuária e o processo de urbanização crescente.

No período de 1960 a 1980, o semiárido apresentou taxas de crescimento do PIB de $8,7 \%$ ao ano. Tal crescimento foi impulsionado, principalmente, por 
incentivos fiscais e créditos públicos (Araújo, 2000; Carvalho \& Egler, 2003), sendo as atividades econômicas mais dinâmicas: bens móveis e serviços às empresas, atividades financeiras, produção de energia elétrica e abastecimento de água, serviços comunitários sociais e pessoais (Araújo, 2000).

No entanto, apesar dos investimentos públicos, nas décadas de 1980 e 1990 as taxas de crescimento declinaram no semiárido (Albuquerque, 2002; Carvalho \& Egler, 2003). Nos anos 1980, o semiárido vivencia a crise do tripé econômico gado/algodão/culturas alimentares. A crise do algodão causou impactos tanto na pecuária quanto na agricultura familiar, sendo que, para os agricultores familiares, a situação era mais grave, pois, apesar da produtividade baixa, a população pobre que vivia das atividades desse sistema produtivo conseguia sobreviver, tirando seu sustento da parte que lhes tocava da produção de algodão e das culturas de subsistência (Araújo, 2000). Desse modo, os agricultores foram obrigados a buscar alternativas de sobrevivência fora da agricultura, fosse dentro do estabelecimento rural ou, até mesmo, migrando para a cidade. Algumas dessas alternativas estavam estruturadas em torno de pequenos negócios não agrícolas. É o caso da produção artesanal de redes, artefatos de couros e alimentos (queijo de manteiga, queijo coalho, manteiga de garrafa e carne de sol), assim como do surgimento de pequenas indústrias de confecções e de alguns ramos do comércio e serviços (Carvalho \& Egler, 2003), consequentemente, contribuindo para a urbanização do semiárido.

De acordo com Carvalho (2015), são notáveis as transformações das médias cidades com a chegada das universidades, por exemplo, o campus do IFPE em Afogados da Ingazeira e o campus da UFCG em Patos, cidades próximas da área de estudo, com o avanço das tecnologias da informação e comunicação, a utilização de bens duráveis, como motocicletas, a disseminação de grandes redes de comércio, como os shoppings centers, e as expressivas transformações na estrutura do consumo, com o surgimento de nova classe consumidora.

Os impactos dessas transformações são decisivos nas atividades econômicas, no meio urbano ou rural, e vale destacar que as populações rurais estão, cada vez mais, compondo a força de trabalho dessas atividades urbanas e, com isso, fortalecendo a pluriatividade no meio rural.

Desse modo, o "velho" semiárido de base gado/ algodão/lavouras alimentares passa a ser um semiárido em transformação, com diversas contradições e uma forte competição entre a agricultura moderna, capitalizada e protegida das estiagens pelos sistemas de irrigação, e a agricultura familiar, dependente das condições ambientais, sem capital e incentivos políticos adequados.

De acordo com Gomes (2015), há um forte declínio relativo de todos os produtos tradicionais da agricultura e um crescimento acentuado dos "novos"3 produtos, especialmente soja, milho, algodão herbáceo e culturas irrigadas. Embora consista numa importante alternativa econômica, a agricultura irrigada é restrita a pequenas extensões de terras irrigáveis e demanda capital e trabalho qualificado, estando concentrada nas mãos de grandes agricultores, o que traz, consequentemente, efeitos negativos sobre a agricultura familiar de sequeiro, como é o caso da agricultura em Brejinho.

Mudanças significativas são observadas, também, nas atividades pecuárias do semiárido. A pecuária bovina, apesar de não ter diminuído de tamanho em termos absolutos, é um setor que tem perdido espaço quando comparado ao Brasil como um todo. A criação de caprinos e ovinos, considerada por muito tempo "atividade de pobre", vem sendo prestigiada e promovida em várias regiões, com significativo melhoramento genético, o que coloca a atividade no limiar do agronegócio. Do mesmo modo, a criação de aves e a apicultura são os setores que mais têm crescido na região (Carvalho, 2015; Gomes, 2015).

Quando se analisam as transformações na base da agropecuária, nota-se que a maior parte destas transita em direção às atividades industriais. Nesse sentido, este complexo setor inclui atividades que vão além da "porteira agrícola": muitas envolvem distribuição de insumos, armazenamento, processamento e distribuição dos produtos agrícolas. Essas atividades vêm se desenvolvendo de forma crescente, no semiárido, nos

\footnotetext{
${ }^{3}$ O autor enfatiza que o milho, a soja e o algodão produzidos atualmente no semiárido são considerados "novos", por serem produtos da agricultura moderna, um negócio capitalizado, tecnologicamente avançado e destinado ao mercado.
} 
últimos anos, algumas vezes com efeitos positivos sobre a agricultura familiar, como é o caso da apicultura e da caprinocultura. Outras vezes, resultam em efeitos negativos, como ocorre com a fruticultura irrigada e os monocultivos de lavouras temporárias (Carvalho, 2015).

Em face do exposto, fica evidente que o meio rural, assim como toda a realidade, está sempre em vias de se transformar. Desse modo, como afirma Carvalho (2015), não se pode mais caracterizar o meio rural semiárido como exclusivamente agrícola. De um lado, existe um conjunto de atividades não agrícolas ligadas à produção agropecuária, como a prestação de serviços e o comércio, que geram novas oportunidades para o agricultor familiar diversificar suas fontes de renda. Por outro lado, o modelo de desenvolvimento agrícola com base na industrialização e no agronegócio, associado a condicionantes macroeconômicos, tem provocado redução na demanda por força de trabalho agrícola e queda dos preços pagos pelos produtos. Com isso, muitos agricultores familiares, sem recursos para garantir sua reprodução, são levados a complementar a renda com atividades fora da agricultura.

\section{Breve caracterização da atividade agrícola nas comunidades pesquisadas}

No que se refere às atividades agrícolas, a pesquisa constatou as características da produção agrícola familiar apontadas por Carneiro (1998) e Schneider (2009b), segundo os quais a família funciona como unidade de produção, consumo e reprodução, buscando produzir quase todos os gêneros alimentícios de que necessita. Os dados mostram grande diversidade, tanto na criação de animais quanto no cultivo agrícola. Os animais são fonte de alimento, mas também força de trabalho, principalmente em época de estiagem, quando existe a necessidade de buscar água e ração em pontos distantes do estabelecimento agropecuário. Além disso, assegura uma renda monetária em curto prazo e uma espécie de poupança em longo prazo. Os dados levantados em campo mostraram que, nas comunidades estudadas, as famílias conciliam, pelo menos, a criação de duas espécies, sendo os rebanhos mais significativos o bovino e o avícola (galinha caipira), presentes em $70,0 \%$ das unidades familiares. Além desses animais, a pesquisa mostrou que 30,0\% das famílias possuem suínos, 20,0\% caprinos e $12,0 \%$ criam ovinos. Os agricultores são estratégicos na hora de se desfazerem dos animais. A venda acontece de acordo com as necessidades imediatas da família, como bem menciona um agricultor do Sítio Lagoa dos Campos: "Se preciso de R\$ 50,00 eu vendo duas galinhas, se preciso de R\$300.00 já tenho que vender uma ovelha e por aí vai".

No tocante às lavouras, as culturas com maior participação nas unidades familiares, segundo os agricultores, são milho, feijão, caju, jerimum e macaxeira. O milho e o feijão, por exemplo, estão presentes em $100 \%$ das unidades familiares pesquisadas. O caju e o jerimum são cultivados em, respectivamente, $44,0 \%$ e $42,0 \%$ das unidades, enquanto o cultivo de macaxeira está presente em $26,0 \%$ das unidades produtivas. Com menor participação em termos quantitativos, mas com grande relevância na segurança alimentar e nutricional, foram mencionadas algumas lavouras permanentes (manga, pinha, limão, laranja, mamão, acerola, seriguela, banana, abacate, goiaba e pitomba), lavouras temporárias (fava, melancia, maracujá, mandioca e batata-doce), hortaliças (cebolinha, coentro, pimentão, tomate cereja, alface e pimenta) e plantas medicinais (hortelã, arruda, boldo do Chile, erva-cidreira, capim-santo, colônia e erva-doce). Além disso, foi citado o cultivo de forrageiras, como palma e capim de corte, cultivos esses importantes para a alimentação animal.

Atestando essa diversidade, a Figura 2 mostra a variedade de espécies cultivadas em uma propriedade familiar da área de estudo, tais como a bananeira, pinheira, milho, feijão e coentro.

Além dos benefícios ecológicos, a diversificação de atividades aumenta o leque de produtos para o autoconsumo, melhorando a segurança alimentar e nutricional do grupo doméstico (produtos diversificados e mais saudáveis), permite agregação de valor dentro do estabelecimento agropecuário, promovendo o aumento da renda dos agricultores, reduz a dependência de insumos externos e propicia a autogestão da propriedade, pois quanto maior for a dependência dos agricultores de fertilizantes, agrotóxicos, sementes, dentre outros, maior será sua vulnerabilidade e maiores serão os custos de produção. As famílias estudadas não fazem 


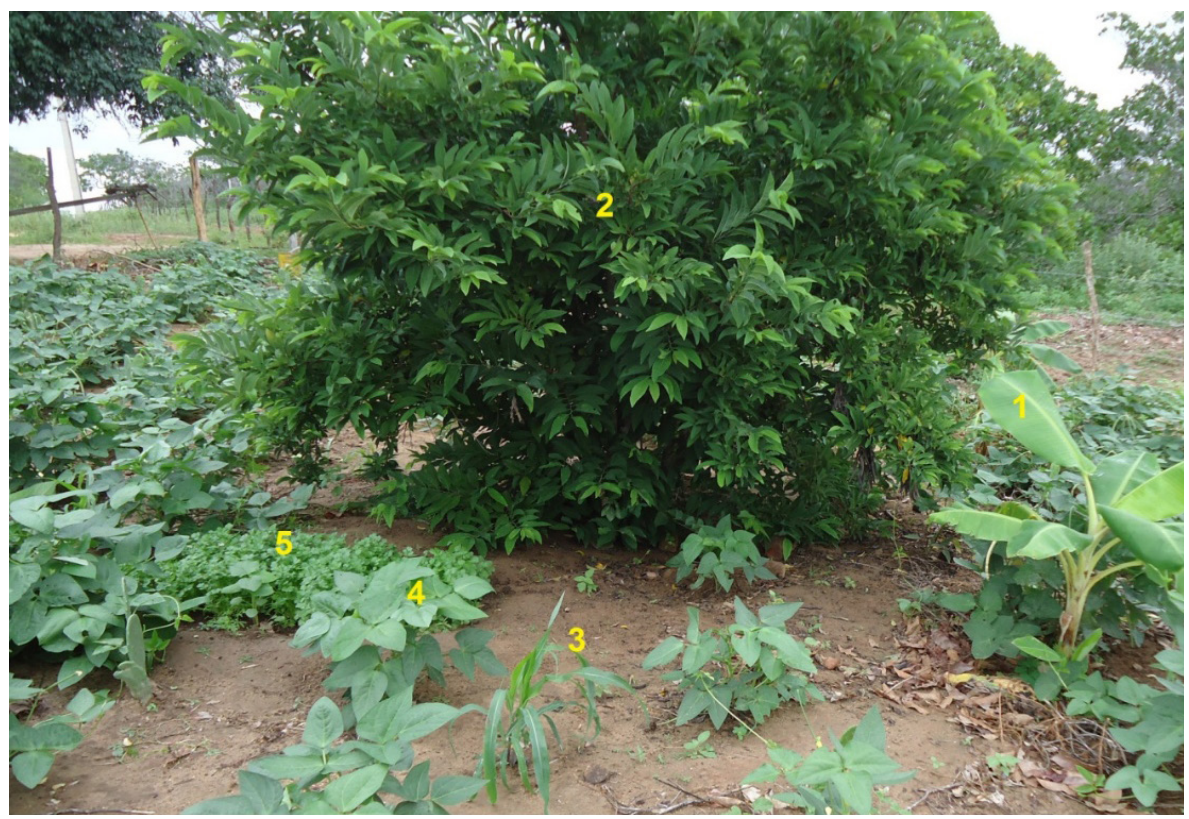

FIGURA 2 - Diversidade da produção agrícola: 1- bananeira; 2 - pinheira; 3 - milho; 4 - feijão; 5 coentro (Sitio Caldeirão, Brejinho/PE). Foto: Valcilene Rodrigues, em março/2014.

uso de agrotóxicos (com exceção de algum formicida) e, quando cultivam hortaliças, a adubação é feita com esterco animal.

O uso de máquinas e equipamentos para preparo do solo e colheita é incipiente, sendo utilizada, nas áreas visitadas ao longo da pesquisa de campo, basicamente a força humana e animal como fontes de energia para o trabalho. Os agricultores relataram que, praticamente, todas as etapas da produção são realizadas com implementos manuais, como a plantadeira, o facão, a enxada e o arado.

Práticas como as citadas atestam as numerosas e complexas interações que existem entre o solo, as plantas e os animais e, ao mesmo tempo, reforçam o importante papel da agricultura familiar na sustentabilidade local. Ressalta-se, no entanto, que o desmatamento da caatinga e as queimadas ainda estão presentes nas comunidades, assim como o plantio "ladeira acima, ladeira abaixo". Essas práticas contribuem para o processo erosivo e reduzem a fertilidade do solo, trazendo danos a todo o ecossistema. Não obstante, ficou evidente na pesquisa que muitos agricultores utilizam práticas inadequadas em suas terras, por falta de conhecimento. Práticas que poderiam, em grande parte, serem evitadas se as famílias contassem com assistência técnica.

\section{Pluriatividade e sustentabilidade da agricultura familiar nas comunidades estudadas}

As atividades agrícolas são fundamentais para a manutenção dos estabelecimentos agropecuários e a reprodução socioeconômica dos agricultores familiares. No entanto, existe uma série de fatores que fragilizam a produção agrícola, levando os agricultores a buscar alternativas de complementação da renda familiar. Como aponta Wanderley (1999, p. 49-50), “o trabalho externo se torna, na maioria dos casos, uma necessidade estrutural, isto é, a renda obtida nesse tipo de trabalho vem a ser indispensável para a reprodução não só da família como do próprio estabelecimento".

Os dados levantados em campo, por meio de entrevistas, conversas e observação participante, pro- 
porcionaram o conhecimento do perfil das unidades familiares. A primeira informação levantada se refere à quantidade de pessoas que compõem essas famílias. A pesquisa indicou uma média de 3,4 membros por unidade familiar, a maior parte $(77,0 \%)$ em idade ativa (15 anos ou mais), o que contribui para o número expressivo de pessoas da família que desenvolvem atividades não agrícolas. As estratégias produtivas e profissionais das famílias vão se modificando de acordo com a evolução da composição etária de seus membros. As famílias com maior número de integrantes em idade ativa, geralmente, têm excedentes de mão de obra disponíveis para trabalhar fora das atividades agrícolas (Schneider \& Radomsky, 2004), ainda mais quando não possuem terra em tamanho suficiente para absorver toda a força de trabalho familiar na agricultura.

Quando analisado o nível de escolaridade dos componentes das unidades familiares, os dados mostraram que $47,0 \%$ dos mesmos possuem, no máximo, ensino fundamental, 40,0\% possuem ensino médio e $13,0 \%$ possuem ensino superior. Esses dados indicam que a pluriatividade abrange tanto atividades que exigem elevados níveis de instrução como atividades com menor exigência de escolaridade. É importante ressaltar que as famílias com níveis mais elevados de instrução tendem a dispor de maiores chances de aumentar e diversificar as fontes de renda. Mas, além do nível de instrução, se faz necessário considerar o ambiente socioeconômico em que os agricultores estão inseridos, como fator adicional de acesso à melhoria e à diversificação da renda.

Outra importante característica das famílias estudadas é a organização social, pois as famílias pesquisadas afirmaram que a mesma é de fundamental importância para reunir esforços e reivindicar melhorias para suas comunidades. Em todas as famílias, pelo menos, um membro participa das organizações sociais locais, na maioria das vezes a mulher, atuando ativamente em Conselhos de Desenvolvimento Rural Sustentável, Associação de Agricultores e Sindicato de Trabalhadores Rurais, na busca por políticas públicas de acesso a água, crédito, assistência técnica, comercialização dos produtos, dentre outros benefícios.

Os meios de transporte e comunicação evoluíram bastante nas últimas décadas e são variáveis importantes para compreender a dinâmica de trabalho das famílias.
Primeiro, porque permitem maior integração entre o urbano e o rural, diminuindo as distâncias físicas. Segundo, porque os agricultores não precisam mais gastar um dia de viagem para irem a cavalo às feiras das sedes municipais, comprar os insumos que consomem ao longo da semana (Carvalho, 2015) ou falar com um filho que está morando fora.

No que se refere aos meios de transporte, os dados da pesquisa mostram que os veículos motorizados estão presentes na maioria $(90,0 \%)$ das unidades familiares pesquisadas, principalmente as motocicletas, que estão em $77,0 \%$ das residências, seguidas de carros $(13,0 \%)$. Esses dados ilustram o aumento no número de motocicletas verificado no Nordeste desde 2001. Segundo o Observatório das Metrópoles (2013), a frota de motos no Nordeste passou de pouco mais de 836 mil, em 2001, para 5 milhões, em 2012. Para os entrevistados, esses veículos são essenciais para conciliar as atividades agrícolas e não agrícolas, uma vez que otimizam o tempo e encurtam as distâncias. Em alguns casos, esse tipo transporte é a própria ferramenta de trabalho, sendo utilizado, por exemplo, no transporte de estudantes, de passageiros (mototáxi), de mercadorias, alimentos, produção agrícola e no deslocamento das pessoas para o trabalho.

Outro elemento de extrema importância para a compreensão do papel da pluriatividade na reprodução das comunidades estudadas diz respeito à estrutura fundiária, uma vez que a mesma é condição sine qua non do processo produtivo na agricultura familiar. No tocante a esse aspecto, os dados mostram que a maioria das famílias $(97,0 \%)$ possui áreas não superiores a 15 hectares, sendo que $54,0 \%$ das famílias estudadas possuem menos de 5 hectares. Assim, a pouca disponibilidade de terra não permite a sobrevivência do agricultor somente com as atividades agrícolas. Apesar disso, os agricultores consideram o meio rural o melhor lugar para se viver e buscam diversas formas para garantir sua permanência no campo. As razões acima apresentadas são elementos que impulsionam e dinamizam as atividades rurais agrícolas e não agrícolas.

No que se refere às ocupações não agrícolas das comunidades estudadas, os dados mostram que as principais atividades estão distribuídas nos ramos comércio de mercadorias, prestação de serviços, indústria de transformação, administração pública e construção civil. Do 
total de famílias entrevistadas, $53,0 \%$ estavam ocupadas por conta própria e $47,0 \%$ eram assalariadas. Nota-se que grande parte das atividades praticadas por conta própria é exercida dentro do estabelecimento agropecuário, enquanto todas as atividades assalariadas são exercidas fora do estabelecimento. Com isso, as famílias que trabalham por conta própria têm maior flexibilidade de tempo para organizar, estrategicamente, as atividades agrícolas e não agrícolas. Isto pode ser constatado na fala de uma entrevistada de Vila de Fátima: "Eu tento conciliar as coisas; depois das limpas no roçado eu foco nas vendas (comércio de confecções); no tempo da colheita já me dedico mais ao roçado e, assim, vou levando".

No caso dos assalariados, a estratégia para conciliar as atividades é um pouco diferente. Os empregados na administração pública, mesmo trabalhando fora do estabelecimento, mantêm-se na propriedade. Logo, têm a possibilidade de gerenciar de perto e participar, sempre que possível, de todas as atividades agrícolas. Já aqueles que estão ocupados na construção civil, geralmente os chefes de família, permanecem nas atividades agrícolas apenas nos primeiros meses do ano, período em que é exigida maior atenção (preparo do solo, plantio, primeira limpa). Após esse período, os trabalhadores se deslocam para as cidades, ficando de seis até nove meses fora do estabelecimento agropecuário. Enquanto isso, os demais membros da família ficam responsáveis pelas atividades agrícolas.

Os dados levantados mostram que $25,0 \%$ das famílias estudadas possuem membros trabalhando na construção civil, com o objetivo de aumentar a renda familiar. O mesmo resultado foi encontrado para a indústria de transformação, especialmente as atividades de fabricação de bolas de futebol e futsal. Esses dados evidenciam que o processo de urbanização propicia a expansão para as áreas rurais de uma série de atividades que, antes, eram exclusivas de áreas urbanas. Estas, por sua vez, vão buscar nas áreas rurais mão de obra não qualificada para as atividades ali desenvolvidas.

O comércio de mercadorias e a prestação de serviços nas comunidades do estudo têm um papel fundamental para as mesmas, não somente pela capacidade de gerarem renda para as famílias ocupadas nessas atividades, mas também por proporcionarem o acesso a bens, alimentos e serviços. Isto sem a necessidade de deslocamento até a cidade, além do fato das famílias se conhecerem, o que cria uma relação de confiança entre as mesmas, nem sempre sendo o dinheiro a moeda de troca. Muitas vezes, a mercadoria ou serviço adquirido tem o pagamento feito em diárias na própria agricultura, evidenciando uma relação contraditória e complementar entre atividades agrícolas e não agrícolas. Desse modo, enquanto a agricultura, fragilizada, impulsiona o surgimento de atividades não agrícolas, estas contribuem para a manutenção das atividades agrícolas.

Quanto à administração pública, observou-se que $50,0 \%$ das atividades assalariadas são exercidas nesse ramo de atividade, o que se explica pelo importante papel do setor público na geração de ocupações não agrícolas no meio rural, nos últimos anos, à medida que a população passou a ter maior acesso aos serviços públicos básicos, como saúde e educação. É justamente nesses dois setores da administração que as famílias estão ocupadas. A Tabela 1 traz, de forma sintetizada, as principais atividades não agrícolas praticadas nas comunidades estudadas.

São vários os fatores que podem explicar o aparecimento da pluriatividade no meio rural. De modo geral, esses fatores podem ser internos, como faixa etária, escolaridade, número de membros da família e disponibilidade de terra, e externos, como contextos ambientais e socioeconômicos em que as mesmas estão inseridas (Carneiro, 1998; Schneider 2009a), a exemplo da expansão ou dinamização do mercado de trabalho. Segundo os agricultores pesquisados, os motivos que os levaram à decisão de desenvolver atividades não agrícolas combinadas com agricultura estão relacionados, principalmente, à necessidade ou possibilidade de complementarem a renda familiar, em virtude da fragilidade da agricultura, situação essa agravada nas secas prolongadas, a exemplo da estiagem que atingia a região, no período 2011-2013. As estiagens deixam as famílias vulneráveis e até mesmo ociosas, pois dificultam a prática da agricultura. Desse modo, muitas famílias encontram nas atividades não agrícolas a principal e, em muitos casos, a única fonte de renda para a própria manutenção, como mostram trechos de entrevistas nas comunidades: "Eu tive que investir mais nisso mesmo [venda de confecções], porque sem inverno não tem agricultura", (Entrevistada do Sitio Caldeirão); "O trabalho 
TABELA 1 - Principais atividades não agrícolas praticadas pelos membros das comunidades pesquisadas - 2014 .

\begin{tabular}{|c|c|c|c|}
\hline $\begin{array}{l}\text { Condição de } \\
\text { ocupação }\end{array}$ & Ramo de atividade & Atividade/Função exercida & Local da atividade \\
\hline \multirow{12}{*}{ Conta própria } & \multirow{3}{*}{$\begin{array}{l}\text { Comércio de } \\
\text { mercadorias }\end{array}$} & Comércio de confecções & Dentro e fora do estabelecimento rural \\
\hline & & Comércio de gêneros alimentícios & Dentro do estabelecimento rural \\
\hline & & Comércio de bebidas & Dentro do estabelecimento rural \\
\hline & \multirow{5}{*}{ Prestação de serviços } & Manicure & Dentro e fora do estabelecimento rural \\
\hline & & Borracharia & Dentro do estabelecimento rural \\
\hline & & Mototáxi & Fora do estabelecimento rural \\
\hline & & Aração de terra por tração animal & Fora do estabelecimento rural \\
\hline & & Costura & Dentro do estabelecimento rural \\
\hline & \multirow{4}{*}{$\begin{array}{l}\text { Indústria de } \\
\text { transformação }\end{array}$} & Fabricação de bolas de futebol e futsal & Dentro do estabelecimento rural \\
\hline & & Serralharia & Dentro do estabelecimento rural \\
\hline & & Fabricação de tijolos & Dentro do estabelecimento rural \\
\hline & & Artesanato & Dentro do estabelecimento rural \\
\hline \multirow{9}{*}{ Assalariado } & \multirow{6}{*}{ Administração pública } & Professor/a & Fora do estabelecimento rural \\
\hline & & Merendeira escolar & Fora do estabelecimento rural \\
\hline & & Zeladora escolar & Fora do estabelecimento rural \\
\hline & & Gari & Fora do estabelecimento rural \\
\hline & & Transporte de estudantes & Fora do estabelecimento rural \\
\hline & & Agente comunitário de saúde & Fora do estabelecimento rural \\
\hline & \multirow{3}{*}{ Construção civil } & Pedreiro & Fora do estabelecimento rural \\
\hline & & Carpinteiro & Fora do estabelecimento rural \\
\hline & & Servente & Fora do estabelecimento rural \\
\hline
\end{tabular}

FONTE: Pesquisa de campo realizada em agosto de 2014.

na roça é assim, você só tem lucro quando colher. É muito bom ter uma renda certa todo mês, por isso sempre que posso viajo para trabalhar na construção" (Agricultor de Vila de Fátima). Além disso, nota-se a vocação e a aptidão pessoal de alguns membros da família para o trabalho não agrícola, como menciona a entrevistada de Lagoa dos Campos: "Eu gosto da agricultura, crio meus animais, mas meu amor pelo magistério é ainda maior".

Não se pode afirmar que a estiagem, por si só, leva à prática da pluriatividade, mas, no semiárido, é sem dúvida um fator que contribui para a decisão da família por essa prática. Considerando que sempre existiu estiagem no semiárido, pode-se perguntar por que as famílias não recorreram sempre à pluriatividade? A resposta a essa pergunta é que, no passado, o contexto social, político e econômico não favorecia tal prática, razão pela qual as famílias encontravam no êxodo rural (definitivo ou temporário) a única alternativa para sobrevivência ao flagelo. No ano de 1993, por exemplo, período de estiagem prolongada na área estudada, as famílias não contavam com políticas públicas como o Programa Bolsa família, o Garantia Safra e o PRONAF, que têm papel importante na injeção de renda nessas comunidades. Além do mais, o acesso a bens e serviços como transporte e energia elétrica era difícil e os contextos de urbanização e do próprio mercado de trabalho também eram distintos do atual. Se, no passado, para conseguir manter a família em períodos de estiagem, os chefes de família se deslocavam para o Sudeste em busca de emprego, o contexto atual permite que as famílias optem pela prática da pluriatividade.

No que se refere à participação da renda dos membros da família nas despesas da unidade familiar, a pesquisa mostrou que todos contribuem nas despesas da casa, mas nem todos participam diretamente da atividade agrícola. Algumas vezes, o trabalho na agricultura, principalmente dos jovens, se resume aos finais de semana. Outras vezes, os membros que trabalham em atividades não agrícolas contribuem com recursos financeiros para 
pagar despesas com a roça. Especialmente no caso dos jovens, exercer outra atividade é uma alternativa para alcançar objetivos individuais, tais como comprar um veículo ou mesmo uma propriedade na comunidade. Ainda assim, esses jovens procuram contribuir de alguma forma com os projetos familiares. Os depoimentos dos pais esclarecem como se dá essa participação, conforme fala de entrevistada residente no Sítio Caldeirão, que assim se expressa: "Minha filha não contribui diretamente com as despesas de casa. Mas ajuda, porque com o salário ela [a filha] paga a faculdade e ajuda o irmão que estuda em tempo integral".

A pesquisa buscou mensurar, também, a participação das rendas não agrícolas no sustento familiar. Como obter dados quantitativos das famílias a esse respeito não é uma tarefa fácil. Foi solicitado que os entrevistados excluíssem do total das rendas obtidas aquelas provenientes de benefícios sociais e aposentadorias e, após isso, informassem o que teria maior participação ou contribuía mais no sustento da família: renda agrícola ou não agrícola. Como resposta, a maioria $(63,0 \%)$ afirmou que as atividades não agrícolas representam de 50\% a $75 \%$ da renda auferida. Para $17,0 \%$ das famílias, as rendas não agrícolas representam mais de $75 \%$ da renda familiar. Outros 20,0\% dos respondentes afirmaram que as rendas não agrícolas representam entre $25,0 \% \mathrm{e}$ $50,0 \%$ e em nenhuma família pesquisada a renda dessas atividades é inferior a 25,0\%.

Vale ressaltar que esses percentuais podem ter sofrido influência dos anos secos, quando a agricultura não apresentou os mesmos rendimentos de anos normais. Contudo, os resultados indicam a importância das atividades não agrícolas para a sobrevivência dos agricultores familiares numa região marcada pela irregularidade da chuva. Outro fator que pode ter influenciado nesses resultados é a dificuldade que o agricultor familiar tem de contabilizar a renda agrícola, podendo a mesma estar subestimada.

Como já mencionado, além das rendas agrícolas e não agrícolas, existem aquelas provenientes dos programas sociais, como o Programa Bolsa Família e a aposentadoria rural, que são fontes de grande importância na manutenção das famílias estudadas. Observa-se que $56 \%$ das famílias entrevistadas recebem o Programa Bolsa Família, 27\% recebem aposentadoria e apenas
$16 \%$ não contam com esses tipos de renda. A importância de tais benefícios decorre não somente do fato de representarem uma renda mensal para as famílias, mas também da capacidade de financiarem, em parte, o desenvolvimento das atividades agrícolas. Do total, $63 \%$ dos entrevistados disseram fazer uso da aposentadoria ou de benefício social nas atividades agrícolas. Em municípios grandes e com economia fortalecida, essas rendas cumprem somente sua função social, mas quando chegam a pequenos municípios, como Brejinho/ $\mathrm{PE}$, se transformam em economia. A injeção de renda nessas localidades, com a elevação do poder aquisitivo, impulsiona tanto as atividades agrícolas como as atividades não agrícolas.

Não é fácil mensurar a sustentabilidade com dados (qualitativos ou quantitativos) tomados isoladamente, por isso é necessário um olhar integrado sobre suas dimensões. Como afirmou Van Bellen (2002), a maioria dos sistemas de indicadores existentes foi desenvolvida para fins específicos nas áreas ambiental, social, econômica e de saúde. Por isso, não podem ser considerados indicadores de sustentabilidade em si mesmos. É indispensável reconhecer suas limitações e a necessidade de mais de um indicador para captar os aspectos mais importantes de uma situação. Além disso, é preciso identificar as conexões existentes entre os mesmos. A disponibilidade de terra, por exemplo, tem implicações importantes na sustentabilidade da agricultura familiar em suas três dimensões, sendo um dos requisitos básicos para a sustentabilidade do semiárido. Trata-se de um indicador que viabiliza ou não o respeito aos limites dos recursos naturais do estabelecimento agropecuário e permite avaliar o equilíbrio entre a produção, a capacidade de resiliência e a reprodução das famílias. Logo, tem relação direta com outros indicadores, como desmatamento, queimadas, qualidade da água, renda, absorção da força de trabalho familiar, dentre outros.

Ocorre o mesmo com outros indicadores. Assim, a diversidade de culturas promove melhorias na segurança alimentar, que está diretamente relacionada com a melhoria na saúde da população, contribui para melhorias do potencial do solo, reduzindo a necessidade de adubação, além de diminuir a incidência de pragas, o que implica, consequentemente, em menos custos com agrotóxicos e fertilizantes e maiores rendimentos econômicos. 
Os indicadores de ocupação e renda são muito importantes para avaliar a dimensão econômica da sustentabilidade, uma vez que mostram se as atividades praticadas estão contribuindo para a melhoria financeira dos agricultores familiares. Da mesma maneira, têm relação direta com os indicadores sociais, pois a ocupação e a geração de renda permitem o acesso a mais produtos e melhores serviços, como moradia, educação e saúde, resultando em melhoria da qualidade de vida.

Diante disso, fica evidente que, embora na situação estudada a sustentabilidade esteja relacionada com um subsistema específico, a agricultura familiar, a mesma exige um enfoque sistêmico, pois o aumento ou redução da sustentabilidade em uma de suas dimensões tem reflexo noutras, bem como na sustentabilidade de outros sistemas.

A dimensão ecológica da sustentabilidade diz respeito ao uso, dos potenciais do ecossistema, com mínima degradação. Quando se analisa a maneira como a pluriatividade é praticada nas comunidades estudadas, verifica-se que a mesma apresenta características que contribuem para a conservação dos recursos naturais. Dentre essas características, destacam-se a diversificação de atividades e a ausência de impactos negativos, tanto da agricultura como das atividades não agrícolas. A maior parte das atividades não agrícolas praticadas é dos ramos pequeno comércio, prestação de serviços e administração pública, atividades essas que não são consideradas potencialmente degradantes. Por outro lado, a agricultura praticada em caráter familiar traz, por si só, a característica da diversificação de recursos e do uso de práticas produtivas de reduzido impacto nos recursos ambientais. Assim, pode-se dizer que a diversidade, além de possibilitar melhor utilização dos recursos disponíveis na unidade familiar, contribuindo para a sustentabilidade ecológica, gera ocupação e oportunidades para permanência dos agricultores no campo.

Para mensurar a dimensão social da sustentabilidade é preciso interligar aspectos como moradia, alimentação, acesso à comunicação, educação, além de aspectos subjetivos, como paz, liberdade, solidariedade, felicidade, dentre outros.

Quanto ao aspecto social, a pesquisa constatou que as famílias em estudo possuem moradia em alvenaria com espaço físico suficiente para os membros e com acesso a serviços básicos de energia elétrica e abastecimento de água para consumo humano por meio das cisternas de placas. Observou-se que, apesar da deficiência no acesso ao saneamento, muitas famílias já possuem banheiro com fossa séptica simplificada, evitando a contaminação dos corpos hídricos e a incidência de doenças. Do mesmo modo, as famílias têm meios de transporte próprio e acesso a meios de comunicação como televisão e telefone celular. $\mathrm{O}$ acesso a esses bens e serviços assegura o bem-estar dos membros das unidades familiares e indica a melhoria na qualidade de vida da população.

Nesse sentido, a pluriatividade tem contribuído de forma positiva na melhoria da qualidade de vida das famílias. Primeiro, porque tem proporcionado aumento da renda familiar e, consequentemente, maior acesso a bens e serviços. Depois, porque tem contribuído para a permanência das famílias no campo, o que proporciona o desfrute das variáveis subjetivas, tais como tranquilidade, sossego, união e liberdade, apontadas pelos agricultores como essenciais para viver bem. Tais variáveis estão associadas com a segurança da população. Os agricultores expressavam orgulhosos o fato de poderem deixar equipamentos fora da casa sem a preocupação de serem roubados ou de terem a liberdade de sair e chegar a qualquer hora sem medo. A liberdade também se refere à autonomia para desenvolver as atividades de acordo com os interesses familiares em jogo.

Como argumentou Foladori (2002), a dimensão econômica da sustentabilidade está associada ao crescimento econômico e à eficiência produtiva. Portanto, consiste no aproveitamento racional das potencialidades naturais e culturais da região, sendo necessário, portanto, adaptar a economia à realidade local. No caso em estudo, a sustentabilidade econômica requer a combinação de diferentes atividades que viabilizem a diversificação das fontes de renda, uma vez que, devido a vários fatores, a agricultura, sozinha, não está conseguindo garantir a reprodução social das famílias. Assim, estando abaixo do patamar de reprodução, os agricultores buscam novas estratégias para garanti-la.

Devido à sazonalidade da produção agrícola de sequeiro e às estiagens periódicas, a combinação de atividades agrícolas com atividades não agrícolas proporciona maior possibilidade de ocupação e geração de renda. De acordo com os agricultores entrevistados, os cultivos 
agrícolas ocupam aproximadamente três meses do ano e, em geral, não absorvem toda força de trabalho da unidade familiar, em virtude do tamanho reduzido das propriedades, ficando o restante do ano apenas para as atividades pecuárias. Desse modo, a prática da pluriatividade assume papel relevante na geração de renda e na ocupação da força de trabalho ociosa no período de entressafra e em épocas de estiagem, contribuindo, decisivamente, para a manutenção familiar. Vale ressaltar, no entanto, que apesar de a pluriatividade impactar positivamente na sustentabilidade econômica das comunidades estudadas, o nível de renda das famílias ainda é muito baixo, como ficou evidenciado pela necessidade de benefícios sociais.

\section{Conclusões}

Como exposto neste artigo, fica evidente que uma série de fatores tem contribuído para o surgimento da pluriatividade no semiárido. Algumas vezes, as práticas de atividades não agrícolas decorre do fato de os membros do grupo familiar verem nessas atividades a possibilidade de melhoria da qualidade de vida. Outras vezes, tal prática decorre de situações impositivas, onde a alternativa encontrada pelos agricultores familiares para manter o modo de vida rural é buscar outras atividades além da agricultura.

\section{Referências}

Ab'Saber, A. N. Os domínios de natureza no Brasil: potencialidades paisagísticas. São Paulo: Ateliê Editorial, 2003.

Albuquerque, R. C. de. Nordeste: sugestões para uma estratégia de desenvolvimento. Fortaleza: Banco do Nordeste do Brasil, 2002.

Araújo, T. B. de. Ensaios sobre o desenvolvimento brasileiro: heranças e urgências. Rio de Janeiro: Revan Fase, 2000.

Barbosa, A. G. Sociedade civil na construção de políticas de convivência com o semiárido. Recife: ASA, 2010.

Bardin, L. Análise de conteúdo. Lisboa, 7. ed. Portugal: LDA, 2009.

Baptista, N. de Q.; Campos, C. H.. Possibilidades de construção de um modelo sustentável de desenvolvimento no semiárido.
$\mathrm{Na}$ realidade estudada, percebe-se uma relação contraditória e complementar entre as atividades agrícolas e não agrícolas, visto que, se, por um lado, a agricultura garante a segurança alimentar das famílias, por outro lado, para ser mantida, essa atividade depende da prática de atividades não agrícolas. Assim, a opção do agricultor familiar pela pluriatividade tem sido uma estratégia importante para garantir a reprodução social e a permanência do grupo familiar no campo.

Outrossim, verifica-se que a pluriatividade contribui para a sustentabilidade em suas três dimensões, na medida em que: a) possibilita às famílias combinarem agricultura com atividades não agrícolas, tendendo, com isso, a minimizar a pressão sobre os recursos ambientais do estabelecimento; b) promove a ocupação da força de trabalho e a geração de renda; c) contribui para a melhoria da qualidade de vida das famílias e para o fortalecimento da economia local.

No entanto, apesar da relevância da pluriatividade para a sustentabilidade das comunidades estudadas, não se pode considerá-la, por si só, a solução dos problemas dos agricultores familiares dessas comunidades, na medida em que os mesmos ainda têm a reprodução social ameaçada pela fragmentação progressiva da terra, evidenciando que muitos desafios precisam ser vencidos para se ter um semiárido, efetivamente, sustentável.

Curso Livre I de autoaprendizagem. Porto Alegre: FAURGS/ RedeGenteSan, 2013a. p. 30-36.

Baptista, N. de Q.; Campos, C. H. Caracterização do semiárido brasileiro. In: Conti, I. L.; Schroeder, O. E. (Orgs.). Convivência com o semiárido brasileiro: autonomia e protagonismo social. Brasília: Editora IABS, 2013b. p. 45-51.

Beltrão, K. I.; Oliveira, F. E. B. de; Pinheiro, S. S. A população rural e a previdência social no Brasil: uma análise com ênfase nas mudanças constitucionais. Rio de Janeiro: IPEA, 2000. Disponível em: <http://www.ipea.gov.br/portal/images/ stories/PDFs/TDs-/td_0-759.pdf>. Acesso em: 11 nov. 2014.

Brasil. Ministério da Integração Nacional. Nova delimitação do semiárido brasileiro. Brasília. 2004. 
Brasil. Secretaria de Agricultura Familiar. Crédito rural. Disponível em: <http://www.mda.gov.br/sitemda/secretaria/ safcreditorural $/$ evolu $\% \mathrm{C} 3 \% \mathrm{~A} 7 \% \mathrm{C} 3 \% \mathrm{~A} 30$-do-pronaf $>$. Acesso em: 16 dez. 2014a.

Brasil. Portal Brasil. Economia e Emprego. Plano Safra 2014/2015 vai destinar $R \$ 24,1$ bi para Agricultura Familiar. Disponível em: <http://www.brasil.gov.br/eco-nomia--e-emprego/2014/05/plano-safra-2014-2015-vai-destinar-r-24-5-bilhoes>. Acesso em: 16 dez. 2014b.

Brasil. Ministério do Desenvolvimento Social e Combate à Fome. Perfil das pessoas e famílias no cadastro único do Governo Federal 2013. Brasília: MDS: 2014c. Disponível em: $<$ http://www.mds.gov.br/biblioteca/secretaria-nacionalderendade-cidadaniasenarc/cartilhas/Perfil_CadastroUnico_2013/ Perfi-1_CadastroUnico_V9.pdf $>$. Acesso em: 16 dez. 2014c.

Buarque, S. C. Metodologia de planejamento do desenvolvimento sustentável. Recife: IICA, 1995.

Carneiro, M. J. Camponeses, agricultores e pluriatividade. Rio de Janeiro: Contra Capa Editora, 1998.

Carvalho, O. de. Tendências, desafios e perspectivas do desenvolvimento urbano e do desenvolvimento rural na região nordeste. Fortaleza: BNB, 2015. (inédito).

Carvalho, O. de; Egler, C. A. G. Alternativas de desenvolvimento para o nordeste semiárido. Fortaleza: Ministério da Fazenda, Banco do Nordeste do Brasil, 2003.

Conti, I. L. Introdução. In: Conti, I. L.; Schroeder, O. E. (Orgs.). Convivência com o semiárido brasileiro: autonomia e protagonismo social. Brasília: Editora IABS, 2013. p. 21-30.

Diegues, A. C. S. O mito moderno da natureza intocada. São Paulo: Hucitec, 1996.

Duque, J. G. Solo e água no polígono das secas. 6. ed. Fortaleza: Banco do Nordeste, 2004.

Foladori, G. Avanços e limites da sustentabilidade social. Revista Paranaense de Desenvolvimento, 102, 103-113, 2002.

Foladori, G. Paradojas de la sustentabilidad: ecológica versus social. Trayectorias, 9(24), 20-30, 2007.

Gomes. G. M. Macroeconomia do Nordeste: tendências, desafios e perspectivas da dinâmica da economia e estrutura produtiva do Nordeste. Fortaleza: BNB, 2015. (Inédito).

INSA - Instituto Nacional do Semiárido. Sinopse do Censo Demográfico para o semiárido brasileiro. Campina Grande: INSA, 2012.
Malvezzi, R. Semiárido: uma visão holística. Brasília: Confea, 2007.

Observatório das Metrópoles. Instituto Nacional de Ciência e Tecnologia. Evolução da frota de automóveis e motos no Brasil, 2001 - 2012. [Relatório 2013] Disponível em: <http://www. observatoriodasmetropoles.net/download/auto_-motos2013. pdf>. Acesso em: 17 nov. 2014.

Sacco dos Anjos, F. Agricultura familiar, pluriatividade e desenvolvimento rural no Sul do Brasil. Pelotas: EGUFPEL, 2003.

Sachs, I. Desarrollo sustentable, bio-industrialización descentralizada y nuevas configuraciones rural-urbanas. Los casos de India y Brasil. Revista Pensamiento Iberoamericano, 16, 235-256, 1989.

Sachs, I. Estratégias de transição para o século XXI: desenvolvimento e meio ambiente. São Paulo: Studio Nobel, 1993.

Sachs, I. Caminhos para o desenvolvimento sustentável. 3. ed. Rio de Janeiro: Garamond, 2008.

Schneider, S. A pluriatividade na agricultura familiar. 2. ed. Porto Alegre: Editora da UFRGS, 2009a.

Schneider, S. A Pluriatividade e as condições de vida dos agricultores familiares do Rio Grande do Sul. In: Schneider, S. A diversidade da agricultura familiar. 2 ed. Porto Alegre: UFRGS, 2009b. p. 139-166.

Schneider, S.; Radomsky, G. F. W. A pluriatividade e as transformações do mercado de trabalho rural gaúcho: estudo de caso no município de Barão, RS. In: Campanhola, C.; Graziano da Silva, J. O novo rural brasileiro: rendas das famílias rurais. Brasília: Embrapa Informação Tecnológica, 2004. p. 263- 319. v. 5.

Sen, A. Desenvolvimento como liberdade. São Paulo: Companhia das Letras, 2010.

Silva, R. M. A. Entre o combate à seca e a convivência com o semiárido: transições paradigmáticas e sustentabilidade do desenvolvimento. 298 p. Brasília, Tese (Doutorado em Desenvolvimento Sustentável) - Centro de Desenvolvimento Sustentável, Universidade Federal de Brasília, 2006.

Sposito. E. S. Geografia e filosofia: contribuição para o ensino do pensamento geográfico. São Paulo: Editora UNESP, 2004.

SUDENE. Uma política de desenvolvimento econômico para o Nordeste. 2. ed. Recife: GTDN, 1967.

Van Bellen, H. M. Indicadores de sustentabilidade: uma análise comparativa. 235 p. Florianópolis, Tese (Doutorado em 
Engenharia de Produção) - Centro Tecnológico, Universidade Federal de Santa Catarina, 2002.
Wanderley, M. de N. B. Raízes históricas do campesinato brasileiro. In: Tedesco, J. C. Agricultura familiar: realidades e perspectivas. Passo Fundo: EDIUPF, 1999. p. 23-56. 